\title{
A novel curation system to facilitate data integration across regional citizen science survey programs
}

\author{
Dana L Campbell ${ }^{\text {Corresp., } 1}$, Anne E Thessen ${ }^{2,3}$, Leslie Ries ${ }^{\text {Corresp. } 4}$ \\ ${ }^{1}$ Division of Biological Sciences; School of STEM, University of Washington, Bothell, Washington, United States \\ 2 The Ronin Institute for Independent Scholarship, Montclair, New Jersey, United States \\ ${ }^{3}$ Center for Genome Research and Biocomputing, Oregon State University, Corvallis, Oregon, United States \\ 4 Department of Biology, Georgetown University, Washington, DC, United States \\ Corresponding Authors: Dana L Campbell, Leslie Ries \\ Email address: danalc@uw.edu, Leslie.Ries@georgetown.edu
}

Integrative modeling methods can now enable macrosystem-level understandings of biodiversity patterns, such as range changes resulting from shifts in climate or land use, by aggregating species-level data across multiple monitoring sources. This requires ensuring that taxon interpretations match up across different sources. While encouraging checklist standardization is certainly an option, coercing programs to change species lists they have used consistently for decades is rarely successful. Here we demonstrate a novel approach for tracking equivalent names and concepts, applied to a network of 10 regional programs that use the same protocols (so-called "Pollard walks") to monitor butterflies across America north of Mexico. Our system involves, for each monitoring program, associating the taxonomic authority (in this case one of three North American butterfly fauna treatments: Pelham, 2014; NABA, 2016; Opler \& Warren, 2003) that shares the most similar overall taxonomic interpretation to the program's working species list. This allows us to define each term on each program's list in the context of the appropriate authority's species concept and curate the term alongside its authoritative concept. We then aligned the names representing equivalent taxonomic concepts among the three authorities.

These stepping stones allow us to bridge a species concept from one program's species list to the name of the equivalent in any other program, through the intermediary scaffolding of aligned authoritative taxon concepts. Using a software tool we developed to access our curation system, a user can link equivalent species concepts between data collecting agencies with no specialized knowledge of taxonomic complexities. 


\section{A novel curation to facilitate data integration across regional citizen science survey}

2 programs

3

4 Dana L. Campbell ${ }^{1}$, Anne E. Thessen ${ }^{2,3}$, Leslie Ries $^{4}$

$6{ }^{1}$ Division of Biological Sciences, School of STEM, University of Washington, Bothell, WA, 7 USA

$8{ }^{2}$ Center for Genome Research and Biocomputing, Oregon State University, Corvallis, OR, USA

$9 \quad{ }^{3}$ The Ronin Institute for Independent Scholarship, Montclair, NJ, USA

$10{ }^{4}$ Department of Biology, Georgetown University, Washington, DC, USA

12 Corresponding Authors:

13 Dana Campbell ${ }^{1}$

14 Division of Biological Sciences, School of STEM, University of Washington, Bothell, WA, USA

15 Email address: danalc@uw.edu

16

17 Leslie Ries ${ }^{4}$

18 Department of Biology, Georgetown University, Washington, DC, 20057

19 Email address: leslie.ries@georgetown.edu 


\section{Abstract}

21 Integrative modeling methods, such as niche modeling, can now enable macrosystem-level

22 understandings of biodiversity patterns, such as range changes resulting from shifts in climate or

23 land use, by aggregating species-level data across multiple monitoring sources. This requires

24 ensuring that taxonomic entities match up across different sources. While checklist

25 standardization is certainly an option, requesting programs to change species lists they have used

26 consistently for decades is rarely successful. Here we demonstrate a novel approach for tracking

27 equivalent names and concepts, applied to a network of 10 regional programs that use the same

28 protocols (so-called "Pollard walks") to monitor butterflies across America north of Mexico. Our

29 system involves, for each monitoring program, identifying the taxonomic authority (in this case

30 one of three North American butterfly fauna treatments: Pelham, 2014; NABA, 2016; Opler \&

31 Warren, 2003) with the most similar taxonomy to the program's working species list. This allows

32 us to define each term on each program's list in the context of the appropriate authority's species

33 concept and associate it with its authoritative concept. We then aligned the names representing

34 equivalent taxonomic concepts among the three authorities. These stepping stones allow us to

35 bridge a species concept from one program's species list to the name of the equivalent in any

36 other program, through the intermediary aligned authoritative taxon concepts. Using a software

37 tool we developed to access our curation system, a user can link equivalent species concepts

38 between data collecting agencies with no specialized knowledge of taxonomic complexities.

39 After integration, taxonomically standardized datasets can subsequently be used as input for 40 many kinds of biodiversity analyses. 


\section{Introduction}

42 There is a long history of piecing together multiple data sets to understand species distributions

43 and patterns at large spatial and temporal extents, including the building of traditional range

44 maps, range changes predicted by niche models (e.g., Graham et al. 2004) and the emerging field

45 of macrosystems ecology that focuses on cross-scale dynamics (e.g., Heffernan et al., 2014).

46 Citizen science-powered monitoring programs now contribute prolific amounts of data towards

47 these ends. Many programs carry out replicated surveys on permanent sites, using formal

48 protocols similar to those in traditional scientific surveys (Kelling et al., 2019). These programs

49 often operate on local scales to collect robust abundance, effort and absence data amenable for

50 developing population indices across space and time, critical metrics for tracking factors such as

51 population declines or shifts in phenology (see Pollock et al., 2002; Schwanghart, Beck \& Kuhn,

52 2008; Pautasso \& Weisberg, 2008). For interpreting changes occurring across populations, there

53 is great value in integrating data from monitoring programs operating at different spatial scales

54 (Downes et al., 2005). This has motivated rapid development of integrative modeling methods to 55 support large-scale analyses (Pautasso \& Weisberg, 2008; Levy et al., 2014; Zipkin \& Saunders, 56 2018; Kéry, 2018).

Despite newly-emerging analytical tools, actual implementations of integrative models are still

59 rare. For example, in Cooper, Shirk \& Zuckergerg's (2014) review of 171 macroscale studies of

60 migratory birds, we note that while 72 of the studies (42\%) used data from regional or

61 continental-scale citizen scientist programs with protocols, $40 \%$ of those are based on a single

62 source of data. Of the remaining studies, more than half used data from banding stations which

63 benefit from centralized taxonomic standards followed by most participating programs. 
64 Published analyses from another highly monitored taxonomic group, the butterflies, also

65 typically include only a single data source. Papers on US butterfly species, including studies

66 examining the influence of environmental variables on entire butterfly communities (e.g.,

67 Forister \& Shapiro, 2003; Forister et al., 2010; Diamond et al., 2014; Cayton et al., 2015;

68 Thorson et al., 2016, Wepprich et al. 2019) all use data originating from a single program and

69 thus did not require any data integration. In studies including data from more than one source

70 (e.g. DeVictor et al., 2012), the data from each source were analyzed separately (Schmucki et al.,

71 2016). We could find only one published study (Mills et al., 2017) that performed an analysis

72 integrating butterfly species concepts across multiple monitoring schemes.

74 Integrating data among multiple sources may be largely constrained by the challenge of 75 consistent taxon matching. The clear trend in data collection is towards observation-based methods (such as citizen science monitoring programs) that do not generate vouchered specimen.

77 Amano, Lamming \& Sutherland (2016) documented that only 50\% of all records in the Global Biodiversity Information Facility (GBIF) are associated with a vouchered specimen, and that number drops to $10 \%$ when looking just over the past decade. Furthermore, we found $98 \%$ of the records put into the GBIF-SCAN (Symbiota Collections of Arthropods Network; the main

81 digitization portal for Lepidoptera occurrence records) in the last 10 years report human observation as basis of record (SCAN-GBIF analysis not presented). This means that in most cases names are the primary identifier for connecting comparable observations across diverse

84 data sources. Integration of data stored in digital repositories such as the GBIF requires

85 resolution of 1) names that contain typographical or formatting issues; 2) synonyms, i.e. different 
86

names used for the same taxonomic concept; and, most complex, 3) names that follow different authorities, that is, the same name used for different taxonomic concepts (Boyle et al., 2013).

For most species-level distribution research, standards for aggregating data consist of resolving deviant spellings, grammatical differences (e.g. hyphens and spaces), or synonymous names, but do not necessarily account for different taxon concepts circumscribed by a species name (Kennedy, Kukla \& Patterson, 2005; Giangrande, 2003; Pyle, 2004, Patterson et al., 2010; Mora et al., 2011; Patterson et al., 2016; Remsen, 2016). Systematic and phylogenetic research continuously reclassifies the biological entities circumscribed by a name; thus unless different data sources explicitly reference the same (or compatible) authoritative treatments, it cannot be assumed that they monitor the same taxonomic concept even when they use the exact same name (Ytow, Morse, \& Roberts, 2001; Pyle, 2004; Kennedy, Kukla \& Paterson, 2005; Franz, Peet \& Weakley, 2008; Franz \& Peet 2009; Boyle, 2013; Cui et al., 2016; Remsen, 2016). This is problematic especially for unstable taxa, for which different taxonomic studies suggest reorganizations and disputed relationships (Ytow, Morse, \& Roberts, 2001).

Franz et al. (2016) illustrated the scope of this problem within the plant Andropogon glomeratusvirginicus "complex" (Poaceae). Careful examination of this species group revealed that multiple different sources of data collected over 126 years were attributed to a single species, but in fact the name under which these data were collected encompassed 12 different taxonomic concepts, because the sources collecting the data used different classifications of the taxa within this complex. Franz et al. (2016) found that names were reliable identifiers of taxonomic concepts in only $60 \%$ of the 12 pairwise alignments, indicating frequent mismatch between the taxonomic 
109 entities and nomenclature. Another study, based on the American Ornithological Union (AOU)'s

110 North American checklist, shows that in the past 127 years 25\% of North American bird names

111 represent taxon concepts that were either split from or combined with another taxon, and of those

112 names, almost half were then subsequently revised at least once (Vaidya, Lepage \& Guralnick,

113 2018). An identical nomenclature used in gathering data before and after a revision may

114 represent non-combinable records for non-identical taxonomic entities. We highlight an example

115 of these issues for butterflies, the Celastrina ladon complex, in which, because of a history of

116 multiple taxonomic interpretations, observations collected under the exact same name often do

117 not actually represent the same species (Fig. 1). We also identify other problematic butterfly

118 complexes encountered by North American monitoring programs.

119

120 Tools have been developed to crosswalk among naming systems, such as Avibase for birds

121 (Lepage, Vaidya \& Guralnick, 2014) and the Taxonomic Names Resolution Service (TNRS) for

122 plants (Boyle et al., 2013), and standardized reference data sets are available to use for

123 vertebrates (Zermoglio, Guralnick \& Wieczorek, 2016). The development of global taxonomic

124 lists, such as the Integrated Taxonomic Information System (itis.gov) and Catalogue of Life

125 (catalogueoflife.org) is another approach to standardize names across databases. More recently,

126 the Global Names Architecture (GNA) was developed with the goal to find, index, and resolve

127 taxonomic discrepancies among digitized taxonomic resources (Pyle, 2016). While these efforts

128 have greatly increased our ability to link knowledge across platforms focused on biodiversity

129 data (Patterson et al., 2016), they have not solved all the problems related to data integration

130 based on identity by name, even for the taxa for which the tools were created. 
132 In this paper, we present a curation-based solution for associating comparable taxonomic

133 identities in the context of citizen science-powered monitoring, exemplified by North American

134 butterfly monitoring programs. Throughout this paper we use the term North American

135 butterflies to mean those north of Mexico. A protocol for surveying butterflies was developed

136 over 40 years ago specifically for volunteer monitors (Pollard, 1977). This was well before the

137 current explosion of citizen science monitoring programs (see Pocock et al. 2014 for

138 development in Great Britain), and represents an early example of using structured protocols (i.e.

139 where permanent routes are set up and monitored regularly using a set protocol, producing the

140 most robust of survey data; Kelling et al. 2019). This protocol, referred to as the "Pollard Walk"

141 or "Pollard Transect," involves monitors walking assigned routes at a steady pace and recording

142 butterflies in a restricted observation window. The UK Butterfly Monitoring Scheme adopted the

143 Pollard Walk methodology in 1976 (Schmucki et al., 2016). Other European countries and

144 regions in the US (usually states) then followed throughout the 1980s, 90s and 2000s (Taron \&

145 Ries, 2015; Van Swaay et al. 2015; Schmucki et al., 2016). In 2014, a web-enabled data entry

146 platform called PollardBase (pollardbase.org) was launched to capture, manage, share, and

147 archive North American butterfly monitoring data. PollardBase has since attracted the

148 membership of most North American, Pollard-based programs (Taron \& Ries, 2015).

150 For butterflies, most structured survey monitoring takes place on a regional basis, so any large-

151 scale analyses will necessarily have to integrate data across programs (Schmucki et al., 2016).

152 Any mismatches or confusion about names could lead to profound biases in the data, especially

153 if a mismatch causes spurious zeros to appear (Royle Nichols \& Kéry, 2005; Pautasso \&

154 Weisberg, 2008). Inflated zeros strongly skew underlying data distributions and would 
155 fundamentally bias any analyses (Kéry, 2018). As large-scale analyses of both pattern and

156 processes are becoming more common, especially through the emergence of the field of

157 macrosystems ecology (Heffernan et al., 2014) and the advancement of integrated statistical

158 models (Zipkin \& Saunders, 2018), the need to make data interoperable without each end-user

159 knowing the complex and often convoluted taxonomic history of all the species in the regional

160 community will become more and more vital (Levy et al., 2014; Kelling et al., 2019). Further, as

161 integrated modeling schemes combine different types of distribution data, including counts,

162 presence/absence, and presence-only data (Kery, 2018; Zipkin \& Saunders 2018), the system we

163 discuss here could potentially help ensure compatibility for curators of many different data types

164 (e.g., iNaturalist, Butterfliesandmoths.org, eButterfly).

165

166 North American butterfly nomenclature is complex and controversial, and significant

167 disagreements have spawned multiple differing lists of species names. As a case in point,

168 estimates of the number of butterfly species in the United States and Canada range from 679

169 (Scott, 1986) to 780 (Opler \& Warren, 2003) to 822 (Pelham, 2014). This is in stark contrast

170 with the nomenclature of European butterflies and of North American birds. For birds,

171 nomenclature is actively standardized by the AOU and the North American Classification

172 Committee (NACC), and Avibase is an additional resource in resolving discrepancies (Lepage,

173 Vaidya \& Guralnick, 2014; Chesser et al. 2016; Lepage, 2017). Without any central taxonomic

174 authority to reference, North American butterfly monitoring programs follow survey lists that

175 reflect the idiosyncrasies, local expertise, and historical practices of their program. Thus naming

176 discrepancies are much more common among butterfly datasets than bird programs and provide

177 an excellent example for testing the effectiveness of our system. 
179 To reduce confusion and ensure conformity of observations, it is common for monitoring

180 programs to record data using their own unique and stable species checklist without regularly

181 updating to newly published names or systematic reorganizations (Ytow, Morse \& Roberts 2001;

182 Taron \& Ries, 2015). Although willing to unite under a shared data management platform,

183 PollardBase programs are disinclined to adopt a single standardized nomenclatural system and

184 there is no way to compel them to do this. Even if it were possible, introducing a standardized

185 nomenclature does nothing to resolve differences in legacy data that have accumulated over 40

186 years of monitoring in the US and Canada. We thus developed our curation system to recognize

187 and automatically match taxonomic entities across PollardBase programs, while allowing each

188 program to retain their own unique checklist. All 21 programs that have joined PollardBase

189 (including the 10 programs in this paper) have agreed to adopt this system. Even in the unlikely

190 case where a group did not wish to cooperate, it would still possible to code their list in a way

191 that adheres to the underlying rules of our system for the purpose of combining data.

192

193 We built our system to resolve alternative names, spellings and taxonomic concepts between any

194 two monitoring programs through the intermediary identification of each program with its

195 underlying authoritative taxonomic treatment. Our system can also address the problem of

196 recording cases where field identification is difficult and a program director chose to have

197 volunteers record certain observations under a name that combines species. Additionally, our

198 system is easily expandable, allowing any monitoring program to opt in at any point. By

199 identifying compatible taxon concepts across programs, our system indicates which data can be 
200 combined, thus providing true data interoperability while "requir[ing] little specialized effort on

201 the part of the end user," a major goal in the field of informatics (Wilkinson et al. 2016).

202

\section{Development of a novel name curation system}

204 To evaluate the usefulness of our system, we show how it works in PollardBase and provide a

205 proof-of-concept that the system can be used to automate the integration of data. Note that the

206 PollardBase platform is designed so that volunteers collecting monitoring data for a particular

207 program can choose only among the official species names included on that program's checklist

208 (which were deliberately specified by the program director). Thus this study, based in the context

209 of 10 PollardBase-registered (for current or future use) programs, allows us to quantify the

210 challenges for data integration present even in this ideal situation where the system controls for

211 data entry level introductions of typographical/spelling errors and for accidental use of an

212 unofficial name (this is the most common source of name discrepancies in data collected outside

213 of platforms like PollardBase). We targeted three specific objectives in developing and testing

214 this new system:

215 - Presentation of a curation system based on an authoritative reference alignment for

216 defining taxonomic concepts

217 - Quantification of the challenges for integrating data across 10 regional butterfly

218 monitoring programs

219 - Development and testing of an automated integration tool to implement our curation $220 \quad$ system. 
222 Objective 1. Presentation of a curation system based on an authoritative reference

223 alignment for defining taxonomic concepts.

224

225 Step 1: Identify authoritative lists of North American (US and Canada) butterflies and

226 assign authority to each program's list. We identified three research-based, taxonomic

227 compendiums that consider the complete butterfly fauna of the United States and Canada: North

228 American Butterfly Association (NABA) Checklist $2^{\text {nd }}$ edition (version 2.3) and updates (NABA

229 2016; henceforth referred to as NABA); Opler \& Warren (2003; henceforth referred to as Opler

230 \& Warren); and Pelham (2014; henceforth referred to as Pelham). More information on these

231 authorities is in Supplemental Article S1. We ascertained for the 10 PollardBase programs that

232 we sample in this paper (described in more detail below), that each uses a checklist similar to one

233 of these authoritative treatments. In addition, we also include in our analyses the Integrated

234 Taxonomic Information System (ITIS) species list (which we restricted to include just American

235 butterfly species north of Mexico), because of its wider familiarity across the community of

236 researchers and potential to serve as a link with other taxonomic databases. Table 1 shows the

237 numbers of names each authority lists at different taxonomic levels.

238

239 PollardBase requests that each registered monitoring program provide its species checklist used

240 for data collection in their locale, and, if known, the source of that list. The source could be a

241 regional authority (e.g., a published regional field guide) or a national, research-based systematic

242 authority. For programs that did not specifically base their list on NABA, Opler \& Warren or

243 Pelham, PollardBase administrators (which include all three authors of this paper) determined

244 which of these three base authorities it most closely resembled, and assigned that as the 
245 program's "base list." None of the 10 programs in this study declare ITIS as an authoritative 246 basis for their own list.

\section{Step 2: Describing types of taxonomic deviations between base authority lists and in} comparisons between programs and their base authority. We manually aligned the three authoritative lists (NABA, Opler \& Warren, Pelham) and the ITIS reference list to identify where nomenclatural differences lie. We used the notes published along with the authoritative lists to help interpret the taxon concepts represented by each list's taxon names and align equivalent concepts across the authorities (Cassie et al., 2001; Opler \& Warren 2003; J Pelham, 2016, pers. comm.). Rarely, we also consulted further literature for clarification. Supplemental Table S1 shows the alignment of all taxa that have one or more discrepancies among the four lists. This alignment acts as the backbone that ultimately allows us to associate taxonomic concepts between two programs whose checklists are based on different authorities (described in Objective 3).

Next, we manually compared each program's list with its specified base list to identify all cases where an entry on a program's species list differed from its specified base authority. Programs were contacted to determine if identified deviations were intentional or if the program director might be willing to modify their list to match their authoritative base list. Note that this represented our only attempt to persuade programs to adopt a different nomenclature, as most programs were very clear before joining PollardBase that they would retain control over their species lists (Ries, personal communication with directors from all 10 North American butterfly 
268 more fully adhere to their matching authority in about $50 \%$ of these cases. Reasons for not

269 changing the name usually stemmed from local custom or the program director's (or local

270 expert's) belief that the name on their list is the appropriate one for them (despite potential

271 conflict with current taxonomic findings). This discussion with the program managers helped

272 PollardBase administrators clarify the precise taxon concept represented by the name on the

273 program list. In cases where we could not identify why the program's list deviated from their

274 base list, we considered the program's discrepancy a discrete difference from its base and

275 assumed the base authority's taxonomic concepts for all other non-divergent taxa. Occasionally

276 ambiguities required us to ask program directors to interpret the implications of their deviation.

277

278 In all, we found six distinct types of deviations which we define, with examples, in Table 2.

279 Some discrepancy types are relevant only between base lists, some only relevant for base

280 list/program list comparisons, and some are relevant in both types of comparisons. We further

281 quantify and characterize these discrepancies in Step 3, below. While many others have noted

282 similar naming differences (for example, Vaidya, Lepage \& Guralnick (2018) discuss lumps and

283 splits of taxa that would fall within and explain much of our "Species or subspecies

284 conglomerates" category and issues of extralimital taxa that we categorize into "Unmatched

285 taxa;" likewise Ytow, Morse \& Roberts (2001) discuss differently circumscribed taxa), we have

286 not seen as comprehensive a categorization of difference types among names as the one we lay

287 out here.

288

289 Step 3: Characterizing and quantifying taxonomic deviations among lists. 
290 Pairwise comparisons between base lists. Comparisons showed 603 species names that are

291 identical (i.e. representing identical taxon concepts) across the three base authority lists and ITIS.

292 This is $71 \%$ of the total number of 849 aligned taxon concepts. Differences in subfamily name

293 were the most common type of deviations among base lists, but only because they were

294 calculated on a per name basis for the entire classification hierarchy, so one change in subfamily

295 name causes as many discrepancies as there are children taxa. Pairwise comparisons of base lists

296 showed between 40 and 257 differences at the subfamily level. Subfamily names generally don't

297 impact the issues of data integration because program lists are based on lower level taxonomy, so

298 hereafter we do not address issues of subfamily deviations but focus instead on pairwise

299 differences at the genus and species level (with some subspecies differences causing species

300 deviations). Table 3 shows the number of each deviation type that occurs between all possible

301 pairwise comparisons of the base lists. ITIS and Opler \& Warren lists are the most similar to

302 each other overall, with a total of $5 \%$ of names differing. Pelham and NABA, the most different

303 lists, deviate at $23.5 \%$ of compared names.

305 As we show later, species type deviations include the most difficult discrepancies to resolve

306 (although many are trivial). Species-level deviations among base lists affected up to $12.7 \%$ of all

307 species. Genus and spelling discrepancies were rarer, up to $4.4 \%$ and $1.6 \%$ respectively, but

308 these deviations are generally easily resolvable once detected because in all cases the alternative

309 names align 1:1 with the taxonomic concept they represent. Deviations due to unmatched taxa

310 are also relatively rare (up to $5.1 \%$ ). We consulted the literature to assure that the missing taxon

311 was actually excluded from the list and not included as a subspecies within another species'

312 concept. 
314 Pairwise comparisons between programs and their base authority. Table 4 shows the types

315 of deviations found between the program lists and their base authorities. Florida's list was the

316 most similar to its base, with $1 \%$ of names showing deviations (Table 4). Orange County

317 (California) has the largest number of deviations for its list size (7.6\% of names). As in base list

318 comparisons, genus deviations and spelling differences between program and base lists were

319 trivial to resolve. However, other deviation classes can be difficult to disentangle, especially if

320 the person who compiled the list is not available to clarify a choice of nomenclature. Species

321 name deviations and unmatched taxa represent the most difficult type of deviation to resolve

322 because they often arise from fundamental disagreement about taxonomic concepts that are not

323 always articulated in a published source. Species and species groups that have been revised

324 multiple times can have a complex history of splitting/lumping disagreements (as demonstrated

325 for birds in Vaidya, Lepage \& Guralnick 2018), creating much confusion when the same species

326 name is used by different programs to refer to a broader or narrower inclusion of subspecies

327 and/or populations. Even if the nomenclature has been taxonomically resolved in the literature,

328 programs retain their own species interpretations. This means that translating accurately from

329 one program to another requires a thorough understanding of each program's interpretation of

330 the nomenclature, complicating the process of establishing the match for each program pair.

331

332 Objective 2. Quantification of the challenges for integrating data across 10 regional

333 butterfly monitoring programs. 
335 One of our goals for this project was to quantify the challenges of taxonomic resolution problems

336 across a sample of programs. For this implementation, we present just the simplest use case: that

337 one of the 10 monitoring programs (the receiver) requests to receive data from one of the other

338 monitoring programs (the donor) using the receiver's taxonomic interpretation to compare

339 compatibility between the two programs. In reality, a more likely scenario is a third party

340 requesting data from multiple programs. We do not consider this more complex case here, which

341 requires the third party to provide their own taxonomic preferences for a final list, but consider

342 this an important feature for future iterations of our tool.

343

344 The 10 regional butterfly programs included in this analysis cover a total of 489 distinct,

345 comparable names, which we aligned manually (see Supplemental Table S2). Of these, $82 \%$

346 either matched exactly across all programs in which they occurred (182 names), or were present

347 in only one program list (208 names). In our alignment we took into account the taxon concept

348 each of the 93 names (18\%) that did not match exactly across programs. These discrepancies are

349 categorized and summarized in Table 5, with more detail provided on the differences in

350 Supplemental Table S3. Most deviation instances were simple issues (category 1 in Table 5), in

351 which programs names differed by simple spelling or synonym variants, but aligned 1:1 with

352 taxon concept. More difficult were subspecies issues (category 2 in Table 5), where some

353 programs listed names that did not align 1:1 across comparisons. The third category of deviations

354 in Table 5 shows the most difficult discrepancies, including conglomerates and complexes,

355 which present much more difficult alignment issues. 
357 Our alignment of program names guided our development of a set of species concept matrices

358 that specify the comparable taxonomic unit for every possible pairwise combination in which

359 one of the 10 programs (receiver) requests data from another program (donor), based on the

360 receiver's taxonomic perspective. We use our set of matrices to quantify the challenges of

361 integration and also as a validation check for our translation tool (Objective 3).

362

363 As an illustration of our process to determine comparable taxonomic units across programs, which

364 starts by identifying taxa that do not exactly align and then translating each case into a taxon concept

365 matrix, we discuss here one of our most difficult taxonomic cases, the Celastrina ladon complex. This

366 complex is composed of seven taxa (approximate ranges shown in Fig. 1), which are treated

367 differently by each of the authoritative base lists. The $C$. ladon complex is problematic partly because

368 the taxonomic entities can be difficult to distinguish morphologically. Pelham and Opler \& Warren

369 elevate all taxa to full species status (although Opler \& Warren does not treat serotina), whereas

370 NABA considers all as subtaxa within C. ladon. In total, our programs monitor five of these taxa

371 (Table 6). Because of conflicting identities, determination of data compatibility between two programs

372 requires careful consideration of the taxonomic concepts used by each program, even when the

373 recorded names are identical.

374

375 For instance, as shown in Figs. 1 and 2, both ladon and neglecta occur in the area monitored by the

376 Iowa program. Iowa, following NABA's taxonomic interpretation, considers these taxa as subspecies,

377 and collects observations for both together under the species name "C. ladon." Conversely, the Florida

378 program, basing its perspective on Opler \& Warren's taxonomy, takes observations of C. ladon and C.

379 neglecta separately, as distinct species. Thus, despite sharing the same name, Iowa's "C. ladon" 
380 observations are not compatible with "C. ladon" observations from Florida. Iowa might consider data

381 compatible only when Florida's data from both C. ladon and C. neglecta are included in comparison

382 with Iowa $C$. ladon data, however a researcher wanting to integrate data could easily overlook this

383 compatibility complication. From Florida's perspective, Iowa's data are not compatible at the species

384 level for either C. ladon or C. neglecta individually. Similarly, the Cascades program, following

385 Pelham's taxonomy, collects distinct observations for C. lucia and C. echo as separate species. Thus,

386 from Cascades' taxonomic interpretation, there are no data from the NABA-based Iowa program that

387 is compatible with either C. lucia or C. echo. On the other hand, Iowa interprets combination as valid

388 as long as both echo and lucia data from Cascades are included with Iowa's C. ladon data. These

389 examples show how the taxonomic interpretation of the monitoring programs fundamentally affect

390 compatibility of the data they collect; data may be compatible between programs when one of the

391 programs is the recipient but not when the other program is; that is, requests may not have a

392 symmetrical solution when flipped the other direction. Furthermore, in the case of the C. ladon

393 complex, half the monitoring programs deviate from the interpretation of their own base authority (see

394 Table 6), emphasizing the potential complexity of deciphering compatibility between program

395 observations.

396

397 We built a species concept integration matrix for the C. ladon complex indicating the

398 compatibility of data collected by each receiver program with data collected by any of the nine

399 potential donor programs (rows and columns, respectively, in Table 7). When the donor program

400 uses the same epithet and taxonomic concept as does the receiver, the outcome is coded in the

401 matrix as a Perfect Match (PM). Where programs do not have an exact match, the receiver's

402 request results in one of the following outcomes: 
403 - No match (Zero). The taxonomic unit does not occur at the donor program. This means that

404 receivers can assume that abundances are always zero for that species throughout the donor

405 program's range.

406 - Compatible match (CM). Compatible matches connect observations that represent the same

407 taxonomic concept as specified by the receiver, but symbolized by the donor with a different

408 nomenclature. This could be due to the use of a different genus or species epithet, the

409 adoption of alternate spelling, or the differential recognition of species/subspecies taxonomic

$410 \quad$ levels.

411 - Multiple match (MM). When there are differences in lumping and splitting taxonomic

412 entities, one program may pool together, under a single name, a concept that is separated into

413 two species by another program. If the program that lumps under one name requests data

414 from a program that splits the species into two, the tool will return both species, which we

415 designate here a "Multiple Match." In the reverse case, where a program that separates the

416 taxa into two names requests a match for one of the names from a program that lumps the

417 taxa together, we flag the response so that the user knows that donor data are only

418 combinable when data from both receiver taxa are included (and thus may not represent a

419 species-level entity from the receiver's perspective). These cases are indicated in Table 7 as

$420 \quad \mathrm{CM}+$

421

422 Supplemental Table S4 lists the 39 species concept integration matrices for all other taxa (18\%

423 of taxon entities) where there are taxonomic names and/or concepts mismatches between

424 programs.

425 


\section{Objective 3. Development and testing of a novel integration tool.}

427

428

429

430

431

432

433

434

435

436

Using our alignment of program names in combination with integration matrices, we built a tool for users to answer, on a case by case basis, whether it is appropriate to integrate data associated with any particular taxon listed on any monitoring program and data gathered by any other monitoring program. The tool is currently available through GitHub (https://github.com/diatomsRcool/butterfly) and mybinder (http://mybinder.org/repo/diatomsRcool/butterfly). This proof-of-concept tool is currently a stand-alone tool, but one that we intend to make fully operable for automating data integration within the PollardBase citizen science butterfly monitoring project infrastructure and can also be implemented on other appropriate portals, such as butterfliesandmoths.org. Thus, the user interface is, as yet, underdeveloped. The tool consists of two parts: 1) a file that contains the mapping between each program list and their base list and from the base lists to a master switchboard list (see Figure 2); and 2) an algorithm that takes user input and uses the mapping file to return the requested results. The following text describes in detail the mapping and the algorithm.

The mapping. We prepared a data file that links names in each program's checklist to the corresponding name in the program's base list. This file also links corresponding base list names across authorities in the master switchboard list. These mappings are codified using parent/child relationships conforming to the Darwin Core biodiversity standard (Wieczorek et al., 2012). This initial linking was done manually as described in Steps 2 and 3 in Objective 1 above. Figure 2 shows two examples for how these links connect names between two program lists through their 
449 associated base lists. Figure 2A shows an example of how we adjusted lists in the mapping file

450 (lower panel, at head of arrow shows we made duplicate $C$. ladon entries), so that they are not

451 exactly true to the original lists (upper panel). This duplication is necessary to account for

452 multiple taxon concept interpretations. Figure 2B shows the mapping of taxa between program

453 lists that have different base lists, using a master switchboard list to 1) disambiguate and manage

454 the multiple concept interpretations of the same name between base lists and 2) allow us to

455 protect the granularity of a program list that may use a less specific base list.

457 As is standard for Darwin Core representations of biodiversity classifications, every name on 458 each program and base list included in our mapping file is assigned a unique Taxon ID, Parent 459 ID, and a Source (Wieczorek et al., 2012). Each name in a program list has a parent in the base 460 list. Each name in the base list has a parent in the switchboard. The Taxon ID and the Parent ID 461 are alphanumeric strings. The Source will always be either a program- or a base-list reference. It

462 is this chain of Taxon ID and Parent ID that the algorithm uses to travel from a Start Program to 463 the switchboard and back down to the End Program.

465 The algorithm. The algorithm takes three pieces of information as input from the user: the 466 recipient program, the taxon of interest, and the donor program. It then uses the mapping file to 467 return the requested result - the equivalent taxon of interest from the donor program. The 468 algorithm searches for the taxon of interest in the recipient program using string matching and 469 then uses the parent identifier to move up the parent/child hierarchy to the switchboard (e.g. Fig.

470 3A). After reaching the switchboard, the algorithm starts traveling back down the parent/child

471 hierarchy by searching for taxa with a specified parent identifier until it finds the appropriate 
472 taxon or taxa in the donor program (Fig. 3B). If no compatible taxa can be found, the system

473 returns: "There is no match in this list (species presumed absent)." This is the case for requests

474 between programs that show "Zero" as the outcome in the concept integration matrix.

475

476 Tool outcomes. In the cases where the matching is too complicated to capture in an algorithm,

477 the tool returns a flag along with the outcome to explain the confusion for that particular pairwise 478 comparison or to suggest that the outcome requires the user to make an individual determination

479 on whether the two taxon concepts are indeed compatible before combining data. For technical

480 reasons, the tool must give symmetrical returns for both directions (i.e. when donor and receiver

481 roles are exchanged) in a pairwise comparisons of programs. In cases where the species matches

482 are not symmetrical in both directions (gray cells in Table 7), the tool returns a flag.

483 Supplemental Article S2 details these two types of flagged outcomes. Note that the tool flags

484 results of difficulties in cases where there is substantial disagreement, even though in our 485 equivalence matrix the comparison might be designated as Compatible or Multiple Match. The

C. ladon complex is complicated by a broad diversity of concept interpretations among base- and

487 program-lists, and every pairwise comparison except two (requests between OC and MPG) results in a flag accompanying the taxon outcome (Table 7).

Testing the Tool. We carried out comprehensive testing on pairwise comparisons across all taxa

491 in all programs, shown in Supplemental Table S5. Each comparison was listed with its expected

492 results. Tests were submitted either in bulk on the command line or singly in a Jupyter notebook.

493 A test was successful if the tool gave a result that matched what was expected based on our pre- 
494 constructed compatibility matrices. Refinement of the tool occurred iteratively until $100 \%$ of

495 comparison tests were successful.

496

\section{Discussion}

498 We have developed a system for the curation of names and associated taxonomic concepts for

499 programs that actively collect data over long time periods. This allows data to be easily

500 integrated between any monitoring programs that adopt this system, even when they use different

501 or even unique nomenclatures. While there are other available systems to resolve taxonomic

502 name conflicts of existing data, they are all retrospective and often rely on assumptions about the

503 collector of the data, who may or may not be available to articulate their concepts when they

504 affixed a name to a data point. Our system is proactive in that it coordinates programs that are

505 continually collecting data by registering their own specified taxonomic names and concepts in

506 relationship to a standardized checklist. By ensuring that PollardBase program directors

507 themselves retain the control of associating taxonomic names between their check list and base

508 lists, we eliminated any disinclination or barriers programs might have in signing on to use our

509 system, and in fact rather than resenting our intrusion, all programs appreciated our help in

510 curating their species lists.

511

512 Combined with PollardBase, which prevents the accidental creation of incorrect name text

513 strings, this system creates a novel taxonomic curation and integration system that maps all,

514 including legacy, concepts between programs while making no demands on the involved

515 monitoring programs and requiring little taxonomic knowledge on the part of the end-user. Our

516 testing shows that our tool can be used to implement our curation system. Using 10 North 
517 American monitoring program checklists and three taxonomic authority lists, our tool accurately

518 recovered comparable taxonomic units between monitoring programs when programs identify

519 taxa at the same taxonomic resolution. When species are identified at different taxonomic levels,

520 our tool flags the data as non-combinable and identify where there may be problems of spurious

521 zeros. Developing a taxonomic backbone that could ensure 100\% correct integration under every

522 situation is extraordinarily complex. As currently designed our tool does not provide a solution

523 for mismatches, but instead leaves it up to the individual researcher to resolve them. Other

524 systems have been designed to deal with this problem (see Ellingsen et al. 2017 for one example)

525 and there is room for improving specific integration guidance for these more complex situations

526 in future iterations of this tool.

527

528 A key advantage of our system is its scalability. Adding a new monitoring program only requires

529 the program to declare one of the taxonomic authorities as its base, and to register any deviations

530 from it. Once that is done, the tool automatically determines name compatibility between the

531 new and pre-existing programs as described above. Similarly, if a new authority list is published

532 that the community begins to use, we can add it as a new base list simply by encoding its

533 relationships via our switchboard. While the potential for much more complicated relationships

534 between concepts increases with additional programs, the structure of the mapping file makes

535 future interoperability tractable.

537 Currently in early stages of development, our tool is a beginning for implementing our curation

538 framework for associating combinable data. Important improvements would include enabling the

539 tool more generally and make it more easily operable by assimilating it with a more developed 
540 interface into the PollardBase and other appropriate platforms; expanding its flexibility by

541 allowing users more customizable taxonomic interpretations; extending taxonomic

542 interoperability to include the perspective of independent third parties interested in the data from

543 these programs; and developing the means for automated updating of taxonomic concepts as they

544 arise in the literature. As case in point, we note the recent revision of the Anthocharis species

545 complex (Stout, 2018) is not reflected in any of our base authorities (although Pelham's most

546 recent (2019) version of his species catalog does include Stout's revision); we updated by

547 flagging the user to consider potential discrepancies.

548

549 Although developed for and tested on the PollardBase network of butterfly monitoring programs,

550 there is nothing about this system that is particular to butterflies. The utility of our system could

551 be implemented to help solve the significant stumbling block of inaccurate taxonomic integration

552 across structured monitoring programs focused on any taxonomic group for which: 1) a

553 taxonomic authority can be identified as the basis for each program's species checklist; 2) any

554 differences among these authorities can be mapped to build an infrastructure to translate between

555 programs; 3) programs can state any deviations between their checklist and their adopted

556 baselist. Regional structured surveying of taxa is becoming increasingly popular (Kelling et al.,

557 2019), and taxa such as odonates and amphibians are particularly amenable to surveys using

558 Pollard-like protocols. Indeed, Pollardbase began accepting odonate and amphibian survey

559 program participants in 2018 and 2019 respectively.

560

561 Citizen science monitoring observations are one of the only sources of large-scale

562 spatiotemporally-replicated biodiversity data available to answer our most important global 
563 change questions. Increasingly complex and powerful models are available to integrate data

564 among regional monitoring programs but accurate results depend on consistent nomenclature to

565 prevent systemic mismatches. Our system is an innovative approach to identify and resolve

566 regionally employed taxon concepts by curating them alongside published authoritative

567 treatments and will guide researchers in tracking North American butterfly populations, while

568 preventing erroneous ecological conclusions drawn from incorrectly associated taxa.

569

\section{Acknowledgements}

571 The authors would like to thank the directors of each of the participating butterfly monitoring

572 programs. Doug Taron especially helped us to develop a system that would be tractable to

573 implement. Program directors at the time we implemented these programs include Doug Taron

574 (Illinois), Jerome Wiedmann (Ohio), Ashley Cole-Wick (Michigan), Sarah Garret (Colorado),

575 Jaret Daniels (Florida), Nathan Brockman (Iowa), Jutta Burger (Orange County), Jeff Pippen

576 (MPG Ranch) and Steve McGaffin (Tennessee). We thank Rob Guralnick and Jeff Pippen for

577 helpful feedback on the project and Jeff Pippen for helping to implement the curation system for

578 new users of PollardBase.

579

580

\section{References}

581 Amano, T., Lamming, J.D. and Sutherland, W.J., 2016. Spatial gaps in global biodiversity

582 information and the role of citizen science. Bioscience, 66(5), pp.393-400.

583

584 Chesser, R.T., Burns, K.J., Cicero, C., Dunn, J.L., Kratter, A.W., Lovette, I.J., Rasmussen, P.C., 585 Remsen, J.V., Rising, J.D., Stotz, D.F. and Winker, K., 2016. Fifty-seventh Supplement to the 586 American Ornithologists' Union Check-list of North American Birds. The Auk, 133(3), pp.544587561. 
589 Boyle, B., Hopkins, N., Lu, Z., Garay, J.A.R., Mozzherin, D., Rees, T., Matasci, N., Narro, M.L., 590 Piel, W.H., Mckay, S.J. and Lowry, S., 2013. The taxonomic name resolution service: an online 591 tool for automated standardization of plant names. BMC bioinformatics, 14(1), p.16.

593 Cassie, B., Glassberg, J., Swengel, A. and Tudor, G., 2001. North American Butterfly

594 Association (NABA) Checklist \& English Names of North American Butterflies.

595 https://www.naba.org/pubs/enames2 3.html

597 Cayton, H.L., Haddad, N.M., Gross, K., Diamond, S.E. and Ries, L., 2015. Do growing degree 598 days predict phenology across butterfly species? Ecology, 96(6), pp.1473-1479.

600 Cooper, C.B., Shirk, J. and Zuckerberg, B., 2014. The invisible prevalence of citizen science in 601 global research: migratory birds and climate change. PloS one, 9(9), p.e106508.

602 https://doi.org/10.1371/journal.pone.0106508

603

604 Cui, H., Xu, D., Chong, S.S., Ramirez, M., Rodenhausen, T., Macklin, J.A., Ludäscher, B., 605 Morris, R.A., Soto, E.M. and Koch, N.M., 2016. Introducing Explorer of Taxon Concepts with a 606 case study on spider measurement matrix building. BMC bioinformatics, 17(1), p.471.

Devictor, V., Van Swaay, C., Brereton, T., Brotons, L., Chamberlain, D., Heliölä, J., Herrando, 609 S., Julliard, R., Kuussaari, M., Lindström, Å. and Reif, J., 2012. Differences in the climatic debts of birds and butterflies at a continental scale. Nature climate change, 2(2), p.121.

611

612 Diamond, S.E., Cayton, H., Wepprich, T., Jenkins, C.N., Dunn, R.R., Haddad, N.M. and Ries, 613 L., 2014. Unexpected phenological responses of butterflies to the interaction of urbanization and 614 geographic temperature. Ecology, 95(9), pp.2613-2621.

615

616 Downes, C.M., Bart, J., Collins, B.T., Craig, B., Dale, B., Dunn, E.H., Francis, C.M., Woodley, 617 S. and Zorn, P., 2005. Small-scale monitoring-can it be integrated with large-scale programs? In: 618 Ralph, C. John; Rich, Terrell D., editors 2005. Bird Conservation Implementation and 
619 Integration in the Americas: Proceedings of the Third International Partners in Flight

620 Conference. 2002 March 20-24; Asilomar, California, Volume 2 Gen. Tech. Rep. PSW-GTR-191.

621 Albany, CA: US Dept. of Agriculture, Forest Service, Pacific Southwest Research Station: $p$.

622 993-996 (Vol. 191).

623 https://www.fs.fed.us/psw/publications/documents/psw_gtr191/psw_gtr191_0993-

6240996 downes.pdf.

625

626 Ellingsen, K.E., Yoccoz, N.G., Tveraa, T., Hewitt, J.E. and Thrush, S.F. 2017. Long-term

627 environmental monitoring for assessment of change: measurement inconsistencies over time and

628 potential solutions. Environmental monitoring and assessment, 189(11), pp.595.

629

630 Forister, M.L. and Shapiro, A.M., 2003. Climatic trends and advancing spring flight of

631 butterflies in lowland California. Global change biology, 9(7), pp.1130-1135.

632

633 Forister, M.L., McCall, A.C., Sanders, N.J., Fordyce, J.A., Thorne, J.H., O’Brien, J., Waetjen,

634 D.P. and Shapiro, A.M., 2010. Compounded effects of climate change and habitat alteration shift

635 patterns of butterfly diversity. Proceedings of the National Academy of Sciences, 107(5),

636 pp.2088-2092.

637

638 Franz, N.M., Chen, M., Kianmajd, P., Yu, S., Bowers, S., Weakley, A.S. and Ludäscher, B., 639 2016. Names are not good enough: reasoning over taxonomic change in the Andropogon 640 complex 1. Semantic Web, 7(6), pp.645-667. https://content.iospress.com/articles/semantic-

641 web/sw220

642

643 Franz, N.M., Peet, R.K. and Weakley, A.S., 2008. On the use of taxonomic concepts in support 644 of biodiversity research and taxonomy, in: The New Taxonomy, Q.D. Wheeler, ed., Systematics

645 Association Special Volume, 76: Taylor \& Francis, Boca Raton, (2008):63-86.

646 doi:10.1201/9781420008562.ch5

647

648 Franz, N.M. and Peet, R.K., 2009. Towards a language for mapping relationships among 649 taxonomic concepts. Systematics and Biodiversity, 7(1), pp.5-20. 
650

651 Giangrande, A., 2003. Biodiversity, conservation, and the 'Taxonomic impediment'. Aquatic

652 Conservation: Marine and Freshwater Ecosystems, 13(5), pp.451-459.

653

654 Graham, C.H., Ferrier, S., Huettman, F., Moritz, C. and Peterson, A.T., 2004. New developments

655 in museum-based informatics and applications in biodiversity analysis. Trends in ecology \& 656 evolution, 19(9), pp.497-503.

657

658 Heffernan, J.B., Soranno, P.A., Angilletta Jr, M.J., Buckley, L.B., Gruner, D.S., Keitt, T.H., 659 Kellner, J.R., Kominoski, J.S., Rocha, A.V., Xiao, J. and Harms, T.K., 2014. Macrosystems 660 ecology: understanding ecological patterns and processes at continental scales. Frontiers in 661 Ecology and the Environment, 12(1), pp.5-14. doi:10.1890/130017.

662

663 Kelling, S., Johnston, A., Bonn, A., Fink, D., Ruiz-Gutierrez, V., Bonney, R., Fernandez, M., 664 Hochachka, W.M., Julliard, R., Kraemer, R. and Guralnick, R., 2019. Using Semistructured 665 Surveys to Improve Citizen Science Data for Monitoring Biodiversity. BioScience, 69(3), 666 pp.170-179.

667

668 Kennedy, J.B., Kukla, R. and Paterson, T., 2005, July. Scientific names are ambiguous as 669 identifiers for biological taxa: their context and definition are required for accurate data 670 integration. In International Workshop on Data Integration in the Life Sciences (pp. 80-95).

671 Springer, Berlin, Heidelberg.

672

673 Kéry, M., 2018. Identifiability in N-mixture models: A large-scale screening test with bird data.

674 Ecology, 99(2), pp.281-288.

675

676 Lepage, D., Vaidya, G. and Guralnick, R., 2014. Avibase-a database system for managing and 677 organizing taxonomic concepts. ZooKeys, (420), p.117.

678

679 Lepage, D. 2017. Avibase - the world bird database. Retrieved from https://avibase.bsc680 eoc.org/avibase.jsp?lang=EN\&pg=home 
681

682 Levy, O., Ball, B.A., Bond-Lamberty, B., Cheruvelil, K.S., Finley, A.O., Lottig, N.R., 683 Punyasena, S.W., Xiao, J., Zhou, J., Buckley, L.B., Filstrup, C.T., Keitt, T.H., Kellner, J.R., 684 Knapp, A.K., Richardson, A.D., Tcheng, D., Toomey, M., Vargas, R., Voordeckers, J.W., 685 Wagner, T. and Williams, J.W., 2014. Approaches to advance scientific understanding of 686 macrosystems ecology. Frontiers in Ecology and the Environment, 12(1), pp.15-23.

687 doi:10.1890/130019.

688

689 Mills, S.C., Oliver, T.H., Bradbury, R.B., Gregory, R.D., Brereton, T., Kühn, E., Kuussaari, M., 690 Musche, M., Roy, D.B., Schmucki, R. and Stefanescu, C., 2017. European butterfly populations 691 vary in sensitivity to weather across their geographical ranges. Global ecology and 692 biogeography, 26(12), pp.1374-1385.

693

694 Mora, C., Tittensor, D.P., Adl, S., Simpson, A.G. and Worm, B., 2011. How many species are 695 there on Earth and in the ocean? PLoS biology, 9(8), p.e1001127.

696

697 NABA Board of directors, Fall/Winter 2006. NABA Butterfly count column 2. American 698 Butterflies, p. 56-57. Available at

699 http://www.naba.org/pubs/ab143_144/ab143_4count_column_program_changes.pdf

700

701 NABA Names Committee. 2015. Interim Report of the NABA Names Committee American 702 Butterflies 22(4): 26-39.

703 https://www.naba.org/ftp/2015a Interim Report NABA Names Committee.pdf.

704

705 NABA Names Committee. 2016. Second Interim Report of the NABA Names Committee 706 American Butterflies 23(3/4): 26-45.

707 http://www.naba.org/ftp/2016_Interim_Report_NABA_Names_Committee.pdf 708

709 North American Butterfly Association, Inc. 2001-2016. Checklist of North American Butterflies 710 Occurring North of Mexico - Edition 2.3 http://www.naba.org/pubs/enames2_3.html. 
712 Opler, P.A. and A.D. Warren, 2003. Lepidoptera of North America. 4. Scientific Names List for

713 Butterfly Species of North America, north of Mexico. Contributions of the C. P. Gillette

714 Museum of Arthropod Diversity, Colorado State University. 79pp.

715

716 Patterson, D.J., Cooper, J., Kirk, P.M., Pyle, R.L. and Remsen, D.P., 2010. Names are key to the

717 big new biology. Trends in ecology \& evolution, 25(12), pp.686-691.

718

719 Patterson, D., Mozzherin, D., Shorthouse, D.P. and Thessen, A., 2016. Challenges with using

720

names to link digital biodiversity information. Biodiversity Data Journal, (4):e8080. doi:

721 10.3897/BDJ.4.e8080.

722

723 Pautasso, M. and Weisberg, P.J., 2008. Negative density-area relationships: the importance of

724 the zeros. Global Ecology and Biogeography, 17(2), pp.203-210.

725

726 Wright, D.M. and Pavulaan, H., 1999. Celastrina idella (Lycaenidae: Polyommatinae): a new

727 butterfly species from the Atlantic coastal plain. The Taxonomic Report, 1(9), pp.1-11.

728

729 Pelham, J.P. 2008. A catalogue of the butterflies of the United States and Canada with a

730 complete bibliography of the descriptive and systematic literature. Journal of Research on the

731 Lepidoptera, vol. 40. xiv + 658. Revised 22 June 2014 and 18 April 2019.

732

733 Pocock, M.J., Roy, H.E., Preston, C.D. and Roy, D.B., 2015. The Biological Records Centre: a

734 pioneer of citizen science. Biological Journal of the Linnean Society, 115(3), pp.475-493).

735

736 Pollock, K.H., Nichols, J.D., Simons, T.R., Farnsworth, G.L., Bailey, L.L. and Sauer, J.R., 2002.

737 Large scale wildlife monitoring studies: statistical methods for design and analysis.

738 Environmetrics: The official journal of the International Environmetrics Society, 13(2), pp.105-

739119.

740

741 Pyle, R.L., 2004. Taxonomer: a relational data model for managing information relevant to

742 taxonomic research. PhyloInformatics, 1, pp.1-54. 
744 Pyle, P. and DeSante, D.F., 2006. Updates to four-letter and six-letter alpha codes based on

745 Revisions by the American Ornithologists' Union. North American Bird Bander, 34(3), pp.109-

746110.

747 http://www.birdpop.org/docs/pubs/Pyle and_DeSante_2009b_Updates to Four_and_Six_Letter

748 Alpha_Codes.pdf

749

750 Pyle, R.L., 2016. Towards a Global Names Architecture: The future of indexing scientific

751 names. ZooKeys, (550), p.261.

752

753 Remsen, D., 2016. The use and limits of scientific names in biological informatics. ZooKeys, 754 (550), p.207.

755

756

Ries, L. and Oberhauser, K., 2015. A citizen army for science: quantifying the contributions of

757

citizen scientists to our understanding of monarch butterfly biology. BioScience, 65(4), pp.419-

758

430. https://doi.org/10.1093/biosci/biv011.

759

760

Royle, J.A., Nichols, J.D. and Kéry, M., 2005. Modelling occurrence and abundance of species

761

when detection is imperfect. Oikos, 110(2), pp.353-359.

762

763

Schmidt, B.C. and Layberry, R.A., 2016. What Azure blues occur in Canada? A re-assessment of

764 Celastrina Tutt species (Lepidoptera, Lycaenidae). ZooKeys, (584), p.135-164. doi:

$76510.3897 /$ zookeys.584.7882.

766

767 Schmucki, R., Pe'er, G., Roy, D.B., Stefanescu, C., Van Swaay, C.A., Oliver, T.H., Kuussaari,

768 M., Van Strien, A.J., Ries, L., Settele, J., Musche, M., Carnicer, J., Schweiger, O., Brereton,

769 T.M., Harpke, A., Heliola, J., Kuhn, E., and Julliard, R. 2016. A regionally informed abundance

770 index for supporting integrative analyses across butterfly monitoring schemes. British Ecological

771 Society Special Feature: Demography Beyond the Population. Journal of Applied Ecology,

772 53(2), pp.501-510. doi: 10.1111/1365-2664.12561.

773 
774 Schwanghart, W., Beck, J. and Kuhn, N., 2008. Measuring population densities in a

775 heterogeneous world. Global Ecology and Biogeography, 17(4), pp.566-568.

776 doi:10.1111/j.1466-8238.2008.00390.x

777

778 Scott, J.A. 1986. Butterflies of North America: A Natural History and Field Guide. Stanford

779 University Press. 583 pp.

780

781 Stout, T.L. 2018. A review of three species-level taxa of the Anthocharis sara complex

782 (Lepidoptera: Pieridae: Pierinae: Anthocharidini). Insecta Mundi. 1133.

783 https://digitalcommons.unl.edu/insectamundi/1133

784

785 Taron, D. and Ries, L., 2015. Butterfly monitoring for Conservation. In Butterfly Conservation in

786 North America (pp. 35-57). Springer, Dordrecht.

787

788 Thorson, J.T., Ianelli, J.N., Larsen, E.A., Ries, L., Scheuerell, M.D., Szuwalski, C. and Zipkin,

789 E.F., 2016. Joint dynamic species distribution models: a tool for community ordination and

790 spatio-temporal monitoring. Global Ecology and Biogeography, 25(9), pp.1144-1158.

791

792 Van Swaay, C., Regan, E., Ling, M., Bozhinovska, E., Fernandez, M., Marini-Filho, O.J.,

793 Huertas, B., Phon, C.-K., Korösi, A., Meerman, J., Pe’er, G., Uehara-Prado, M., Sáfián, S., Sam,

794 L., Shuey, J., Taron, D., Terblanche, R., and Underhill, L. 2015. Guidelines for Standardised

795 Global Butterfly Monitoring. Group on Earth Observations Biodiversity Observation Network,

796 Leipzig, Germany. GEO BON Technical Series, 1, p.32.

797

798 Vaidya, G., Lepage, D., and Guralnick, R. 2018. The tempo and mode of the taxonomic

799 correction process: How taxonomists have corrected and recorrected North American bird

800 species over the last 127 years. PLoS One 13(4): e0195736.

801 https://doi.org/10.1371/journal.pone.0195736

802

803 Wepprich, T., Adrion, J., Ries, L., Wiedmann, J. and Haddad, N., 2019. Butterfly abundance

804 declines over 20 years of systematic monitoring in Ohio, USA. BioRxiv, p.613786. 
805

806 Wieczorek, J., Bloom, D., Guralnick, R., Blum, S., Döring, M., Giovanni, R., Robertson, T. and

807 Vieglais, D., 2012. Darwin Core: an evolving community-developed biodiversity data standard.

808 PloS one, 7(1), p.e29715.

809

810 Wilkinson, M.D., Dumontier, M., Aalbersberg, I.J., Appleton, G., Axton, M., Baak, A.,

811 Blomberg, N., Boiten, J.W., da Silva Santos, L.B., Bourne, P.E. and Bouwman, J., 2016. The

812 FAIR Guiding Principles for scientific data management and stewardship. Scientific data, 3.

813

814 Ytow, N., Morse, D.R. and Roberts, D.M., 2001. Nomencurator: a nomenclatural history model

815 to handle multiple taxonomic views. Biological journal of the Linnean Society, 73(1), pp.81-98.

816

817 Zermoglio, P.F., Guralnick, R.P. and Wieczorek, J.R., 2016. A standardized reference data set

818 for vertebrate taxon name resolution. PloS one, 11(1), p.e0146894.

819

820 Zipkin, E.F. and Saunders, S.P., 2018. Synthesizing multiple data types for biological

821 conservation using integrated population models. Biological Conservation, 217, pp.240-250. 


\section{Table 1 (on next page)}

Numbers of taxa recognized by each base list and ITIS 


\begin{tabular}{|l|r|r|r|r|r|r|r|r|r|}
\hline Base List & $\begin{array}{c}\text { Sub } \\
\text { families }\end{array}$ & \multicolumn{1}{c|}{ Tribes } & Sub tribes & Genera & Sub genera & $\begin{array}{c}\text { Species } \\
\text { groups }\end{array}$ & Species & Sub species & Total \\
\hline Pelham & 23 & 46 & 37 & 247 & 38 & 36 & 820 & 1570 & 2817 \\
\hline NABA & 24 & 0 & 0 & 221 & 0 & 0 & 725 & 112 & 1082 \\
\hline OW & 22 & 2 & 0 & 231 & 0 & 0 & 784 & 2 & 1041 \\
\hline ITIS & 25 & 44 & 3 & 235 & 0 & 0 & 804 & 1541 & 2652 \\
\hline
\end{tabular}

1 


\section{Table 2 (on next page)}

Types of discrepancies observed in pairwise comparisons between authoritative base lists (NABA, O\&W and Pelham) and between program checklists and their base authority.

Note: some comparisons showed more than one type of discrepancy. 


\begin{tabular}{|c|c|c|}
\hline $\begin{array}{c}\text { Type of } \\
\text { discrepancy } \\
\text { (abbreviation) }\end{array}$ & Definition & Examples \\
\hline $\begin{array}{l}\text { Subfamily name } \\
\text { deviation (F) }\end{array}$ & $\begin{array}{l}\text { Lists use different subfamily names } \\
\text { Definition relevant only. for } \\
\text { comparisons between base authority } \\
\text { lists. }\end{array}$ & $\begin{array}{l}\text { O\&W don't recognize subfamily } \\
\text { Polyommatinae; all taxa designated as } \\
\text { Polyommaninae by NABA, Pelham and ITIS are } \\
\text { considered Lycaenidae by O\&W. }\end{array}$ \\
\hline $\begin{array}{l}\text { Genus name } \\
\text { deviation }(G)\end{array}$ & $\begin{array}{l}\text { Lists use different genus names } \\
\text { (usually species epithet is the same). } \\
\text { Definition relevant for base list } \\
\text { comparisons and base/project list } \\
\text { comparisons. }\end{array}$ & $\begin{array}{l}\text { 1) ITIS, Pelham, O\&W base lists distinguish } \\
\text { genus Zerene from genus Colias, while NABA } \\
\text { does not. } \\
\text { 2) Illinois list deviates from NABA base in using } \\
\text { Plebejus melissa instead of Lycaeides melissa }\end{array}$ \\
\hline $\begin{array}{l}\text { Species epithet } \\
\text { deviation }(\mathbf{S})\end{array}$ & $\begin{array}{l}\text { Lists use different specific epithets } \\
\text { and/or subspecies usage, due to: } \\
\text { 1) differences in recognition of rank } \\
\text { level for subspecies (subspecies } \\
\text { promotion). } \\
\text { 2) errors of determination. } \\
\text { 3) different synonym is used. } \\
\text { 4) differences in subspecies use - } \\
\text { One list extends to subspecies, the } \\
\text { other does not. } \\
\text { Note: "Species" definition refers } \\
\text { only to cases in which different } \\
\text { species names are used purposefully; } \\
\text { differences due to spelling are } \\
\text { treated separately below. } \\
\text { Definition relevant for base list } \\
\text { comparisons and base/project list } \\
\text { comparisons. }\end{array}$ & $\begin{array}{l}\text { 1) Subspecies promotion: NABA recognizes } \\
\text { subspecies Hesperia comma colorado, while } \\
\text { Pelham and O\&W promote this to H. colorado. } \\
\text { Note: this means a) different species names exist } \\
\text { for the "colorado" taxon concept; and b) the } \\
\text { term "H. comma" represents more than one } \\
\text { concept. } \\
\text { 2) Misdetermination: Hawaiian Erionota torus is } \\
\text { listed as E. thrax by all base taxonomies except } \\
\text { O\&W, who note it was originally misdetermined } \\
\text { as E. thrax by Linnaeus (1767). } \\
\text { 3) Different synonyms: ITIS, Pelham, O\&W use } \\
\text { Piruna aea, NABA uses P. cingo. } \\
\text { 4) Subspecies use deviations. In these cases, } \\
\text { how/ whether names can be integrated across } \\
\text { lists may depend on geography or concept: MPG } \\
\text { lists Speyeria cybele leto, while all other } \\
\text { monitoring groups list } S \text {. cybele. }\end{array}$ \\
\hline $\begin{array}{l}\text { Spelling/historical } \\
\text { differences in } \\
\text { scientific names } \\
\text { (L) }\end{array}$ & $\begin{array}{l}\text { Lists use alternate spellings. } \\
\text { Definition relevant for base list } \\
\text { comparisons and base/project list } \\
\text { comparisons. As mentioned in text, } \\
\text { project list spellings are sanctioned, } \\
\text { not introduced by individual } \\
\text { monitors. }\end{array}$ & $\begin{array}{l}\text { NABA list spells Atrytonopsis edwardsi whereas } \\
\text { Pelham and O\&W spell A. edwardsii. }\end{array}$ \\
\hline $\begin{array}{l}\text { Species or } \\
\text { subspecies } \\
\text { conglomerates } \\
\text { (C) }\end{array}$ & $\begin{array}{l}\text { One project list combines two or } \\
\text { more species or subspecies together } \\
\text { (that are separated in base lists). } \\
\text { Definition relevant only for } \\
\text { base/project comparisons. }\end{array}$ & $\begin{array}{l}\text { In every case encountered in our study, this } \\
\text { divergence type occurred due to unreliability of } \\
\text { distinguishing the taxa in the field. } \\
\text { E.g. Illinois lumps Colias eurytheme and } C \text {. } \\
\text { philodice (as } C \text {. eurytheme/philodice) although } \\
\text { Illinois' base list (NABA) treats them as distinct } \\
\text { species. }\end{array}$ \\
\hline $\begin{array}{c}\text { Unmatched } \\
\text { Taxon } \\
\text { (U) }\end{array}$ & $\begin{array}{l}\text { Base or program list includes a } \\
\text { species not on another base list, even } \\
\text { under another name. } \\
\text { Definition relevant for base list } \\
\text { comparisons and base/project list } \\
\text { comparisons. }\end{array}$ & $\begin{array}{l}\text { This deviation usually happens when a list } \\
\text { includes a taxon that rarely/never occurs in } \\
\text { North America. } \\
\text { E.g. Pelham includes Kisutam syllis (a rare stray } \\
\text { to southern Texas). }\end{array}$ \\
\hline
\end{tabular}




\section{Table 3 (on next page)}

Numbers of deviations by discrepancy type seen in pairwise comparisons of authority lists (including ITIS)

We calculate percentage for each discrepancy type as a function of the maximum number of species for each list pair (maximums shown in Table 1; e.g., for Pelham/NABA comparison, species number is 820 ). 


\begin{tabular}{|l|c|c|c|c|c|}
\hline & $\begin{array}{c}\text { Genus } \\
\text { Deviation (G) }\end{array}$ & $\begin{array}{c}\text { Species } \\
\text { Deviation (S) }\end{array}$ & $\begin{array}{c}\text { Spelling } \\
(\mathbf{L})\end{array}$ & $\begin{array}{c}\text { Unmatched } \\
\text { Taxon (U) }\end{array}$ & $\begin{array}{c}\text { Total } \\
\text { deviations }\end{array}$ \\
\hline Pelham/NABA & $35(4.3 \%)$ & $104(12.7 \%)$ & $12(1.5 \%)$ & $42(5.1 \%)$ & $193(23.5 \%)$ \\
\hline Pelham/OW & $17(2.1 \%)$ & $34(4.1 \%)$ & $3(0.4 \%)$ & $32(3.9 \%)$ & $86(10.5 \%)$ \\
\hline OW/NABA & $26(3.2 \%)$ & $85(10.8 \%)$ & $11(1.4 \%)$ & $18(2.3 \%)$ & $140(17.9 \%)$ \\
\hline ITIS/Pelham & $15(1.8 \%)$ & $12(1.5 \%)$ & $1(0.1 \%)$ & $20(2.4 \%)$ & $48(5.9 \%)$ \\
\hline ITIS/NABA & $29(3.6 \%)$ & $94(11.7 \%)$ & $13(1.6 \%)$ & $25(3.1 \%)$ & $161(20.0 \%)$ \\
\hline ITIS/OW & $2(4.4 \%)$ & $20(2.5 \%)$ & $2(0.2 \%)$ & $16(2.0 \%)$ & $40(5.0 \%)$ \\
\hline
\end{tabular}




\section{Table 4 (on next page)}

Deviations between each project list and its base list, by discrepancy type.

See Table 2 for definitions of discrepancy types. 


\begin{tabular}{|l|l|c|c|c|c|c|c|c|c|c|}
\hline \multicolumn{1}{|c|}{ Project } & $\begin{array}{c}\text { Project } \\
\text { abbreviation }\end{array}$ & $\begin{array}{c}\text { Base } \\
\text { List }\end{array}$ & $\begin{array}{c}\text { Total } \\
\text { taxa }\end{array}$ & $\begin{array}{c}\text { Total } \\
\text { deviations }\end{array}$ & $\begin{array}{c}\text { Deviations } \\
\text { per \# taxa } \\
(\%)\end{array}$ & $\begin{array}{c}\text { Genus } \\
\text { Name (G) }\end{array}$ & $\begin{array}{c}\text { Species } \\
\text { Name (S) }\end{array}$ & $\begin{array}{c}\text { Spelling } \\
\text { (L) }\end{array}$ & $\begin{array}{l}\text { Unmatched } \\
\text { Taxon (U) }\end{array}$ & Species \\
\hline Cascades & CAS & Pelham & 151 & 8 & 5.3 & 4 & 2 & 1 & 1 & 0 \\
\hline Colorado & CO & O\&W & 245 & 10 & 4.1 & 0 & 6 & 2 & 2 & 0 \\
\hline Florida & FL & O\&W & 192 & 2 & 1 & 0 & 0 & 0 & 2 & 0 \\
\hline Illinois & IL & NABA & 142 & 5 & 3.5 & 1 & 0 & 2 & 0 & 2 \\
\hline Iowa & IA & NABA & 118 & 2 & 1.7 & 2 & 0 & 0 & 0 & 0 \\
\hline Orange County (CA) & OC & O\&W & 79 & 6 & 7.6 & 0 & 2 & 0 & 4 & 0 \\
\hline Michigan & MI & NABA & 135 & 3 & 2.2 & 0 & 1 & 1 & 0 & 1 \\
\hline MPG Ranch (MT) & MPG & Pelham & 116 & 4 & 3.5 & 3 & 0 & 2 & 0 & 4 \\
\hline Ohio & OH & NABA & 165 & 7 & 4.2 & 1 & 1 & 4 & 1 & 0 \\
\hline Tennessee & TN & NABA & 135 & 9 & 6.7 & 5 & 0 & 2 & 0 & 2 \\
\hline
\end{tabular}




\section{Table 5 (on next page)}

Summary of discrepancies across monitoring programs

For more detail, see Supplemental Table S3. Note: issues here are those that pertain only to our 10 program lists. Authority list comparisons have taxonomic conflicts between taxa that are not sampled by these program lists. 


\begin{tabular}{|c|c|c|c|c|}
\hline Discrepancy types & $\begin{array}{l}\text { Number of } \\
\text { incidences }\end{array}$ & $\begin{array}{l}\text { Number of } \\
\text { names used }\end{array}$ & $\begin{array}{c}\text { Number of } \\
\text { concepts }\end{array}$ & Notes \\
\hline \multicolumn{5}{|l|}{ 1. Simple issues (names align 1:1 with taxon concept) } \\
\hline Genus deviations: different genus names used & 8 & 16 & 8 & Combinable. \\
\hline Species deviations: alternate synonym or spelling used & 8 & 19 & 8 & $\begin{array}{l}\text { Combinable. For one taxon (Phyciodes selenis), programs used } \\
\text { four name deviations that we consider (combinable) synonyms, } \\
\text { however users should be aware that other researchers may } \\
\text { recognize taxon concept distinctions among these terms }\end{array}$ \\
\hline \multicolumn{5}{|l|}{ 2. Subspecies Issues } \\
\hline $\begin{array}{l}\text { Some programs specify taxon to subspecies level } \\
\text { (names align 1:1 with concepts at all comparisons) }\end{array}$ & 10 & 20 & 20 & $\begin{array}{l}\text { Combinable at species- and/or subspecies-level comparisons when } \\
\text { appropriate subspecies data is parsed at both programs. } \\
\text { User should ensure level of analysis is clear. }\end{array}$ \\
\hline $\begin{array}{l}\text { Some programs list more than one subspecies } \\
\text { (subspecies names do not align 1:1 with species-level } \\
\text { concept) }\end{array}$ & 2 & 6 & 6 & $\begin{array}{l}\text { Combinable at species- and/or appropriate subspecies-level } \\
\text { comparisons. } \\
\text { Both subspecies must be included in species-level comparisons } \\
\text { with other programs. User combine with care. }\end{array}$ \\
\hline \multicolumn{5}{|c|}{$\begin{array}{l}\text { 3. Taxonomic issues: identification, alternate species names, taxonomic revisions, subspecies promotion interpretations (Names do not align 1:1 with taxonomic } \\
\text { concept) }\end{array}$} \\
\hline $\begin{array}{l}\text { Conglomerates (species level ID difficult to } \\
\text { distinguish in field so some programs collect } \\
\text { combined data) }\end{array}$ & 2 & 6 & 6 & $\begin{array}{l}\text { For some program combinations, data must be analyzed at levels } \\
\text { higher than species concept. } \\
\text { A third taxon conglomerate occurs in } C \text {. ladon species complex; } \\
\text { numbers of names and concepts for this conglomerate are included } \\
\text { in complexes category below. }\end{array}$ \\
\hline Complexes (different taxon concept interpretations) & 7 & 19 & 18 & $\begin{array}{l}\text { Includes issues of subspecies promotion, taxonomic revisions and } \\
\text { different interpretations of species concepts. Tool interprets } \\
\text { compatibility based on the taxonomic interpretation of program } \\
\text { receiving data and geographic range when appropriate. }\end{array}$ \\
\hline Celastrina ladon species complex & 1 & 7 & 8 & $\begin{array}{l}\text { Within the } C \text {. ladon species complex some programs also } \\
\text { conglomerate taxon collection for ladon and neglecta }\end{array}$ \\
\hline
\end{tabular}




\section{Table 6(on next page)}

The taxonomic entities from the $C$. ladon complex occurring in each program range, and nomenclature used by each program.

(D) indicates that the program's interpretation deviates from that of its declared authoritative base. Dorsal (left wing) and ventral (right wing) images show wing variation among taxa (although much variation also exists within each taxon, a source of the taxonomic confusion). No dorsal image available for humulus. Photo credits: C. ladon, $C$. neglecta, C. Iucia, Schmidt \& Layberry, 2016; C. echo, CBG Photography Group, Centre for Biodiversity Genomics, CreativeCommons BY-NC-SA; C. humulus, Jeffrey Pippen. 


\begin{tabular}{|c|c|c|c|c|c|c|}
\hline & \multicolumn{5}{|c|}{ Taxonomic entity and nomenclature used by each program } \\
\hline & & ladon & neglecta & lucia & echo & humulus \\
\hline Program & Base authority & & & & & \\
\hline Illinois & NABA (D) & \multicolumn{2}{|c|}{ C. ladon/neglecta } & & & \\
\hline Iowa & NABA & \multicolumn{2}{|c|}{ C. ladon } & & & \\
\hline Ohio & NABA (D) & C. ladon & C. neglecta & & & \\
\hline Michigan & NABA (D) & \multicolumn{2}{|c|}{ C. ladon/neglecta } & & & \\
\hline Tennessee & NABA (D) & \multicolumn{2}{|c|}{ C. ladon } & & & \\
\hline Florida & $\mathrm{O} \& \mathrm{~W}$ & C. ladon & C. neglecta & & & \\
\hline Cascades & Pelham & & & C. lucia & C. echo & \\
\hline MPG Ranch, MT & Pelham & & & & C. echo & \\
\hline Colorado & $\mathrm{O} \& \mathrm{~W}$ & C. ladon & & & & C. humulus \\
\hline Orange $\mathrm{Co}, \mathrm{CA}$ & $\mathrm{O} \& \mathrm{~W}(\mathrm{D})$ & & & & C. ladon echo & \\
\hline
\end{tabular}

1 


\section{Table 7 (on next page)}

Data integration matrix for the Celastrina ladon complex showing matches between each pairwise combination of monitoring programs

In total, our ten monitoring programs use five taxonomic names (ladon, neglecta, echo, lucia, humulus) to represent multiple taxon concepts in the C. Iadon complex. No program contains more than two taxa within its range. Each cell in the matrix indicates the outcome of a request for equivalent data from the "Receiver program" (R) in rows, to the "Donor program" (D), in columns. Where there is no match in the donor program, the cell is marked "Zero." Types of match (CM, PM, MM) are defined in text. A plus symbol (+) next to the match type indicates that the receiver program must include data from more than one of its surveyed taxa for compatibility with the donor's match, thus the receiver may consider the donor's content as not combinable at their species-level interpretation. A pair of programs may have compatibility in one direction but not in the other (that is, if donor and receiver roles are reversed). Gray cells indicate these situations where the match is not symmetrical in both directions of request. Comparisons between programs that share NABA as their base list (top left quadrant, boarded with thick lines) have less conflict than comparisons between programs whereby one program has a NABA base and the other program has Pelham or OW base list. 


\begin{tabular}{|c|c|c|c|c|c|c|c|c|c|c|}
\hline & & & & & Donor & & & & & \\
\hline $\begin{array}{l}\text { Celastrina ladon } \\
\text { comples taxa occuring } \\
\text { at each progect }\end{array}$ & $\frac{\text { IL (NABA) }}{\text { C. ladon/neglecta }}$ & $\frac{\text { IA (NABA) }}{\text { C. ladon }}$ & $\frac{\text { MI (NABA) }}{\text { C. ladon/neglecta }}$ & $\begin{array}{l}\text { OH (NABA) } \\
\text { C. ladon } \\
\text { C. neglecta }\end{array}$ & $\frac{\text { TN }(\mathbf{N A B A})}{\text { C. ladon/neglecta }}$ & \begin{tabular}{|l|} 
FL $(\mathbf{O W})$ \\
C. ladon \\
C. neglecta
\end{tabular} & \begin{tabular}{|l} 
CAS (Pelham) \\
C. lucia \\
C. echo
\end{tabular} & \begin{tabular}{|l} 
MPG \\
$\frac{\text { (Pelham) }}{\text { C. echo }}$
\end{tabular} & \begin{tabular}{|l} 
CO $(\mathbf{O W})$ \\
C. ladon \\
C. humulus
\end{tabular} & $\frac{\mathrm{OC}(\mathbf{O W})}{\text { C. ladon echo }}$ \\
\hline $\begin{array}{l}\text { IL (NABA) } \\
\text { C. ladon/neglecta }\end{array}$ & $\mathbf{x}$ & $\mathrm{CM}$ & PM & MM & PM & MM & MM & $\mathrm{CM}$ & MM & $\mathrm{CM}$ \\
\hline \begin{tabular}{|l|l|l|} 
IA (NABA) \\
C. ladon
\end{tabular} & $\mathrm{CM}$ & $\mathbf{X}$ & $\mathrm{CM}$ & MM & $\mathrm{CM}$ & MM & MM & $\mathrm{CM}$ & MM & $\mathrm{CM}$ \\
\hline $\begin{array}{l}\text { MI (NABA) } \\
\text { C. ladon/neglecta }\end{array}$ & PM & $\mathrm{CM}$ & $\mathbf{x}$ & MM & $\mathrm{PM}$ & MM & MM & $\mathrm{CM}$ & MM & $\mathrm{CM}$ \\
\hline $\begin{array}{l}\text { OH (NABA) } \\
\text { C. ladon } \\
\text { C. neglecta }\end{array}$ & $\mathrm{CM}^{+}$ & $\mathrm{CM}+$ & $\mathrm{CM}+$ & $\mathbf{X}$ & $\mathrm{CM}^{+}$ & $\begin{array}{l}\mathrm{CM} \\
\mathrm{PM}\end{array}$ & $\begin{array}{l}\text { MM } \\
\text { Zero }\end{array}$ & $\begin{array}{l}\mathrm{CM} \\
\text { Zero }\end{array}$ & $\begin{array}{l}\text { MM } \\
\text { Zero }\end{array}$ & $\begin{array}{l}\mathrm{CM} \\
\text { Zero }\end{array}$ \\
\hline $\begin{array}{l}\text { TN (NABA) } \\
\text { C. ladon/neglecta }\end{array}$ & $\mathrm{PM}$ & $\mathrm{CM}$ & $\mathrm{PM}$ & MM & $\mathbf{X}$ & MM & MM & $\mathrm{CM}$ & MM & $\mathrm{CM}$ \\
\hline \begin{tabular}{|l|} 
FL $(\mathrm{OW})$ \\
C. ladon \\
C. neglecta \\
\end{tabular} & $\mathrm{CM}+$ & $\mathrm{CM}+$ & $\mathrm{CM}+$ & $\begin{array}{l}\mathrm{CM} \\
\mathrm{PM}\end{array}$ & $\mathrm{CM}+$ & $\mathbf{x}$ & $\begin{array}{l}\text { Zero } \\
\text { Zero }\end{array}$ & $\begin{array}{l}\text { Zero } \\
\text { Zero }\end{array}$ & $\begin{array}{l}\text { PM } \\
\text { Zero }\end{array}$ & $\begin{array}{l}\text { Zero } \\
\text { Zero }\end{array}$ \\
\hline $\begin{array}{l}\text { CAS (Pelham) } \\
\text { C. lucia } \\
\text { C. echo } \\
\end{array}$ & $\begin{array}{l}\text { Zero } \\
\text { Zero }\end{array}$ & $\begin{array}{l}\text { Zero } \\
\text { Zero } \\
\end{array}$ & $\begin{array}{l}\text { Zero } \\
\text { Zero } \\
\end{array}$ & $\begin{array}{l}\text { Zero } \\
\text { Zero }\end{array}$ & $\begin{array}{l}\text { Zero } \\
\text { Zero } \\
\end{array}$ & $\begin{array}{l}\text { Zero } \\
\text { Zero }\end{array}$ & $\mathbf{x}$ & $\begin{array}{l}\text { Zero } \\
\text { PM }\end{array}$ & $\begin{array}{l}\text { Zero } \\
\text { Zero }\end{array}$ & $\begin{array}{l}\text { Zero } \\
\mathrm{CM}\end{array}$ \\
\hline \begin{tabular}{|l|} 
MPG (Pelham) \\
C. echo \\
\end{tabular} & Zero & Zero & Zero & Zero & Zero & Zero & PM (echo) & $\mathbf{X}$ & Zero & $\mathrm{CM}$ \\
\hline $\begin{array}{l}\text { CO }(\mathbf{O W}) \\
\text { C. ladon } \\
\text { C. humulus }\end{array}$ & $\begin{array}{l}\text { Zero } \\
\text { Zero }\end{array}$ & $\begin{array}{l}\text { Zero } \\
\text { Zero }\end{array}$ & $\begin{array}{l}\text { Zero } \\
\text { Zero }\end{array}$ & $\begin{array}{l}\mathrm{CM} \\
\text { Zero }\end{array}$ & $\begin{array}{l}\text { Zero } \\
\text { Zero }\end{array}$ & $\begin{array}{l}\text { PM } \\
\text { Zero }\end{array}$ & $\begin{array}{l}\text { Zero } \\
\text { Zero }\end{array}$ & $\begin{array}{l}\text { Zero } \\
\text { Zero }\end{array}$ & $\mathbf{X}$ & $\begin{array}{l}\text { Zero } \\
\text { Zero }\end{array}$ \\
\hline$\frac{\mathbf{O C}(\mathbf{O W})}{\text { C. ladon echo }}$ & Zero & Zero & Zero & Zero & Zero & $\mathrm{CM}$ & MM & $\mathrm{CM}$ & $\mathrm{CM}$ & $\mathbf{X}$ \\
\hline
\end{tabular}




\section{Figure 1}

Map of North America showing locations of monitoring programs and C. ladon taxa.

Monitoring areas of the ten programs included in this paper are shaded in gray. Program abbreviations are given in Table 4. Approximate geographical distributions of the seven taxa included in the $C$. ladon complex (colored circles) are shown as described in the original base lists (more recent taxonomic updates may conflict with these distributions). Note that serotina and idella do not occur within the monitoring areas of any of these programs. 


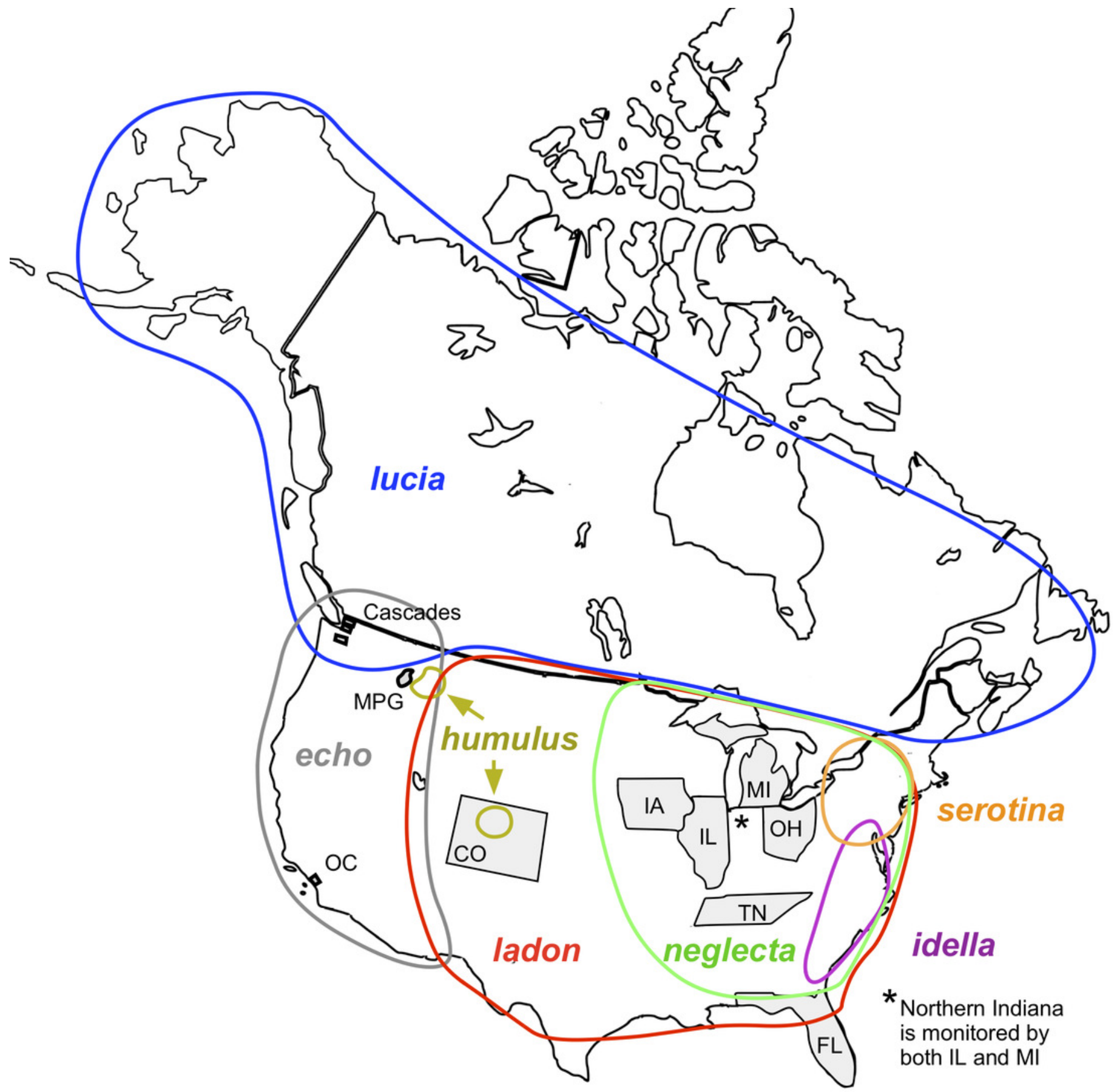




\section{Figure 2}

Examples of taxa translation across programs in the tool's name-mapping data file.

In some cases, a project list deviates from its base list such that multiple taxa on the project list match to a single species on the corresponding base. For example, Ohio's list includes $C$. Iadon and C. neglecta. (A) Top panel illustrates that if we were to directly translate at the species level from Ohio's taxa to its (NABA) base equivalent, we would, in the process, eliminate Ohio's differentiation of $C$. ladon and $C$. neglecta, since NABA considers these subspecies of $C$. Iadon. To retain granularity and manage relationships that are not differentiated by name string, we duplicate the name in the base list, allowing mapping of each project concept to a distinct base list holder (second panel, end of gray arrow). (B) When two programs have different base lists, we translate between them by introducing a "switchboard" that manages relationships and granularity between taxa in the base lists. Our algorithm (demonstrated in Fig. 5) uses this structure to find equivalent names between programs. 
a.

Base list: NABA

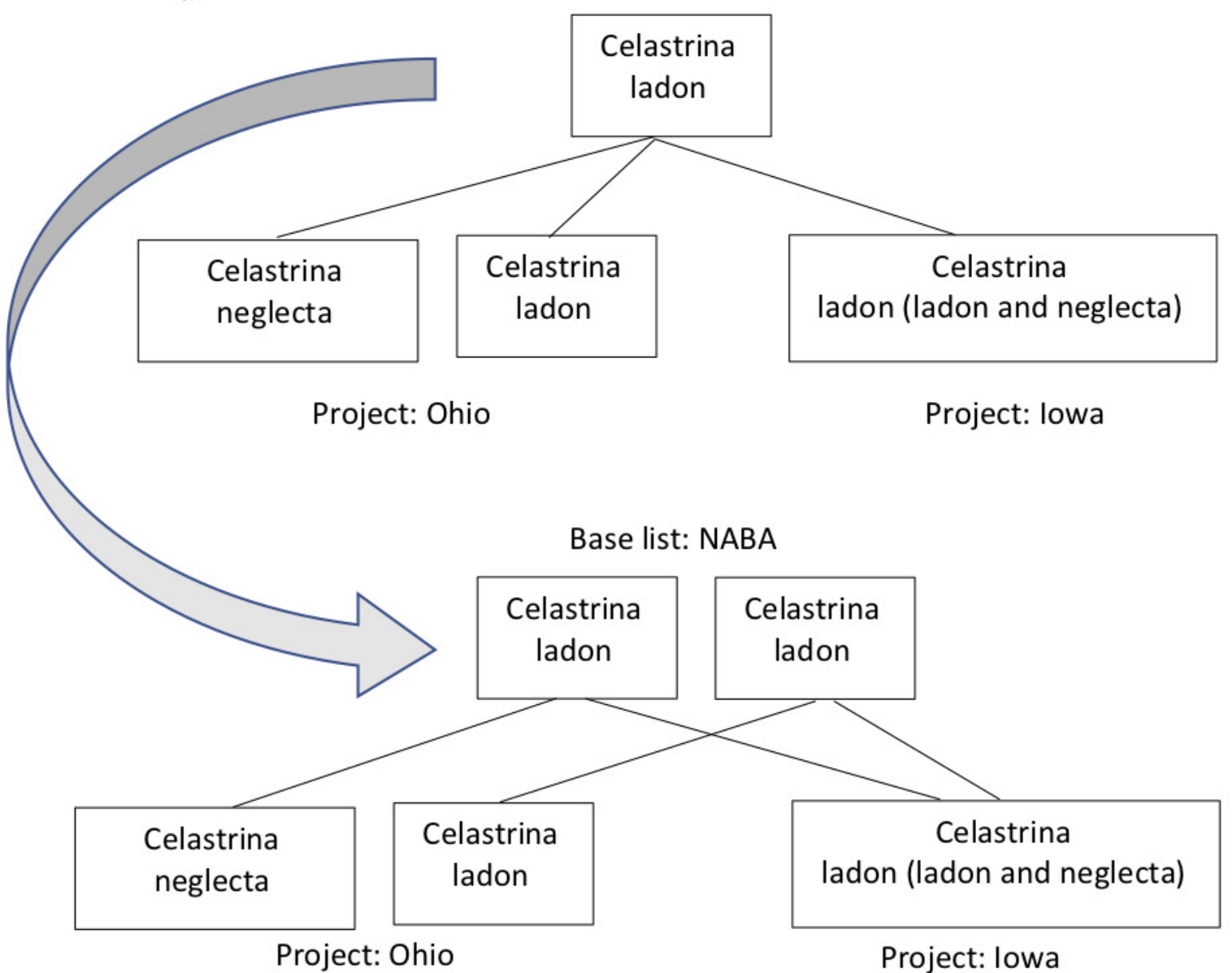

b.

Switchboard

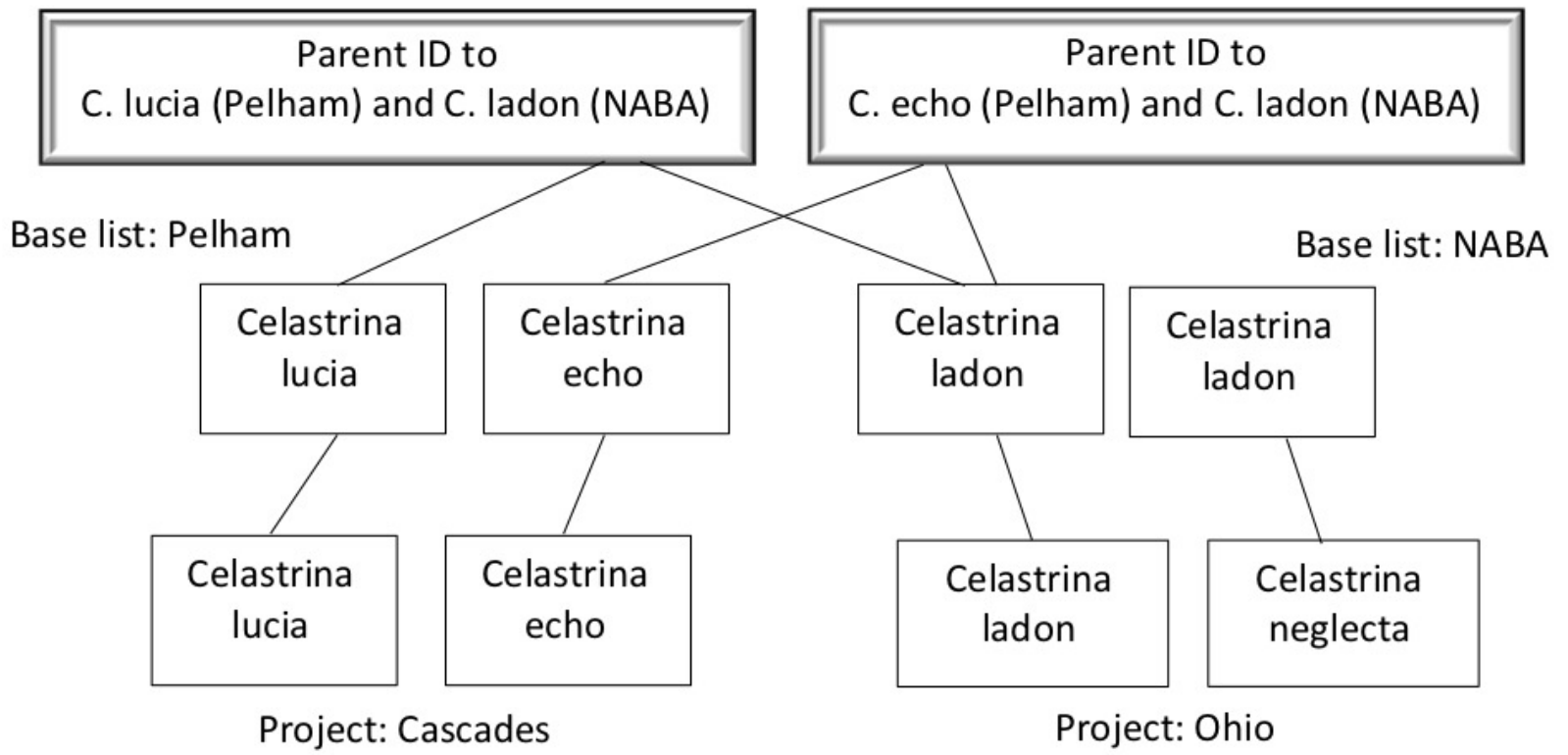




\section{Figure 3}

Tool algorithm for translating between two program lists through the switchboard example query

This query uses the mapping file described in Figure $2 b$. The user has entered three pieces of information: a taxon name (C. lucia); the "Recipient program" (Cascades Butterfly Project); and the "Donor program" (Ohio Butterfly Monitoring Network). A. The algorithm first works its way up the hierarchy to the switchboard, starting with the input taxon name C. lucia (1) and "Recipient" program (Cascades Butterfly project) to find the appropriate data row in the mapping file. The parent identifier (2) for C. lucia at Cascades (T2936) is used to find the row for the corresponding taxon in the Pelham base list (3). The parent identifier for the base list (4; T1267) acts as the taxon ID at the switchboard (5, and dashed red line). B. The algorithm searches for rows that have the switchboard taxon identifier as the parent identifier ( $\left.1^{\prime}\right)$. These results are filtered, because the user identified a "Donor program," (Ohio) which has a defined base list (i.e., the algorithm knows to look only for a row where NABA is the source). Once the appropriate base list taxa have been found, its taxon identifier $\left(2^{\prime} ; \mathrm{T} 1267\right)$ is used to find its child in the (Ohio) project list ( $3^{\prime} ;$ T3784). The name associated with the appropriate parent identifier (4' T6762) is returned as the result (5'; Celastrina ladon). 


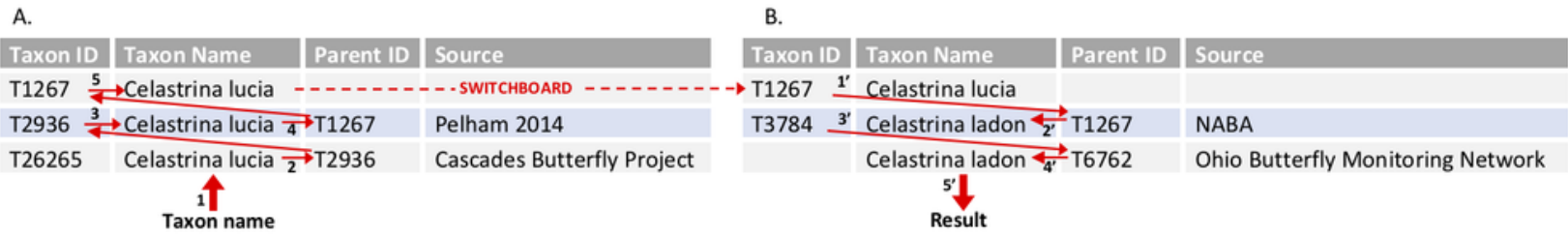

